\title{
Liver Dysfunctions in Dengue Infection: An Update on its Pathogenesis
}

\section{Rituraj Niranjan*, Panneer D and Purushothaman Jambulingam}

Unit of Microbiology and Molecular Biology, ICMR-Vector Control Research Center, Puducherry, India

*Corresponding author: Rituraj Niranjan, Unit of Microbiology and Molecular Biology, ICMR-Vector Control Research Center, Puducherry, India, Tel: 91-4312272397; Email: riturajniranjan@rediffmail.com

Received date: October 20, 2017; Accepted date: October 24, 2017; Published date: October 25, 2017

Copyright: ( 2017 Niranjan R, et al. This is an open-access article disturbed under the terms of the Creative Commons Attribution License, which permits unrestricted use, distribution, and reproduction in any medium, provided the original author and source are created.

Abbreviations: ALT: Alanine aminotransferase; AST: Aspartate aminotransferase; NK: Natural killer cells; DENV-2: Dengue virus-2; NS1: Nonstructural protein 1; CD: Clusture of differentiation

\section{Mini Review}

Dengue fever (dengue hemorrhagic fever or dengue shock syndrome) is a virus infection and comes under one of the major vector-borne diseases [1,2]. Dengue infection has now become the global health threat [2]. High fever, chills, rash and strong headache are the more common clinical features of this disease [3,4]. In addition to these symptoms, some special clinical manifestations appear in response to severe dengue cases where viremia is high [5]. Liver dysfunction is one of the atypical forms of clinical manifestation in the dengue infection [3]. The clinical feature of hepatic dysfunctions in dengue patients are increased liver size and elevated levels of liver enzymes mainly transaminases $[4,6]$. The increase in size of gallbladder was also observed as early clinical manifestations in dengue patients [7]. Around $46 \%$ of dengue infected patients from Indonesia were diagnosed to have enlarged liver size. [8]. The other atypical clinical symptoms of dengue were nausea and abdominal pain [9]. Some dengue patients also manifest jaundice and hyperbilirubinemia $[4,10]$. However, the number of patients is still very less having liver dysfunction with dengue infections [3]. A wide number of reports have suggested the role of immune cells and mediators of inflammation in the liver dysfunctions however, the exact mechanism is still not clear [11-13]. In this article, we discuss some facts and role of immune components involved in the dysfunctions of liver in dengue fever [14].

In a study, a number of liver parameters such as abnormal high transaminases enzyme and development of subsequent hepatic encephalopathy were observed in dengue infected patients [11,15]. Acute abnormality in the levels of serum alanine aminotransferase (ALT) and aspartate aminotransferase (AST) was observed in the patients with dengue hemorrhagic fever and dengue shock syndrome $[16,17]$. The presence of acute liver failure was confirmed in case of dengue hemorrhagic fever [18]. The severe cases of dengue infection resulted in mortality due to multiple organ failures including liver. A report from Myanmar on the autopsy have described that there is liver damage in these dengue cases and was associated with the huge number of complement components on hepatocytes of the alternative pathways as well as of classical pathways [19]. The cases from the Saudi Arabia have also involved the many more liver dysfunctions and show abnormal liver function with high transaminases and elevated creatine kinase [20]. The genome-wide association studies suggested the activating natural killer (NK) cells receptors involvement in the dengue diseases [21]. The dengue hemorrhagic fever has also been associated to the acute liver failure [18]. The elevated levels of liver enzymes ere also found in the dengue patients in the Vietnam $[7,22]$. The metabolic functions of the patients are also altered in case of dengue infection [23]. It is further interesting to note that, dengue virus infection may be more severe in the hepatitis patients as it induces the apoptosis in the same as evident from a case report in which dengue antigen was found in the hepatocytes [24].

Studies from experimental models have suggested that dengue does a lot of liver dysfunctions via direct or via altering immune functions. In a mice model of study, it was observed that a dengue-specific CD8+ $\mathrm{T}$ cell possesses the pathogenic roles in case of dengue virus infections [25]. It was further observed that, secreted non-structural 1(NS1) antigen protein of dengue virus has the ability to attach to the liver cells via interactions with heparan sulfate and chondroitin sulfate $\mathrm{E}$ and thus modulate the functions [26]. Another important study have described that, the secreted form of dengue virus non-structural protein NS1 is engulfed by hepatocytes, that further accumulate in the endosomes showing an important mechanism for the development of dengue associated pathophysiology [14]. A study from the DENV-2 infected mouse model have revealed that focal alterations in the liver along with the infection, In addition to this, ultra structural observations disclosed the alerted hepatocytes [27]. In this model dengue virus antigen was detected in the hepatocytes and thus is associated with the altered liver functions [27]. It has recently been understood that dengue infected dendritic cells activate other cells via direct contact mediated mechanism as evident that, dendritic cells activate natural killer cells via the mechanism however its mechanism of disease is not yet properly known [28]. Therefore, it is also suggested that it can be an important mechanism of disease via which dendritic cells activate other cells by physical contact or by way of its mediators [28]. Evidence from an immunocompetent mice model of study has shown that there is a massive liver damage which is responsible for death $[29,30]$. Moreover hepG-2 cells also show the adaptation in dengue infected cases [31]. Co-infection with the other infectious agents shows an important area in the case of dengue infection [30,31]. It has also been important that dengue virus protein modulate the liver cells via the epigenetic mechanism of the liver cells [32]. All together it can be said that, liver dysfunctions is an important aspect in the dengue virus infection and therefore some strategies should be made for the management of liver dysfunctions.

\section{Acknowledgment:}

The young scientist grant No: SB/YS/LS-198/2014 to Dr. Rituraj Niranjan by SERB (DST, India.) is gratefully acknowledged.

\section{References}

1. Wiwanitkit V (2007) Liver dysfunction in Dengue infection: an analysis of the previously published Thai cases. J Ayub Med Coll Abbottabad 19: $10-12$. 
2. Thisyakorn U, Thisyakorn C (2015) Dengue: Global Threat. Southeast Asian J Trop Med Public Health.46 : 3-10.

3. Ahmed A, Alvi AH, Butt A, Nawaz AA, Hanif A (2014) Assessment of Dengue fever severity through liver function tests. J Coll Physicians Surg Pak 24: 640-644.

4. Sahana KS, Sujatha R (2015) Clinical profile of dengue among children according to revised WHO classification: analysis of a 2012 outbreak from Southern India. Indian J Pediatr 82: 109-13.

5. Ahmad S, Dhar M, Srivastava S, Bhat NK, Shirazi N, et al. (2013) Dengue hepatitis sans dysfunction: experience of a single tertiary referral centre in the north Indian state of Uttarakhand. Trop Doct 43: 62-65.

6. Saikia N, Talukdar R, Singal DK, Chaudhary D, Bhullar SS, et al. (2007) Hepatic calcification following dengue virus-induced fulminant hepatic failure. Indian J Gastroenterol 26: 90-92.

7. Binh PT, Matheus S, Huong VT, Deparis X, Marechal V (2009) Early clinical and biological features of severe clinical manifestations of dengue in Vietnamese adults. J Clin Virol 45: 276-80,

8. Chairulfatah A, Setiabudi D, Ridad A, Colebunders R (1995) Clinical manifestations of dengue haemorrhagic fever in children in Bandung, Indonesia. Ann Soc Belg Med Trop 75: 291-295.

9. Saha AK, Maitra S, Hazra S (2013) Spectrum of hepatic dysfunction in 2012 dengue epidemic in Kolkata, West Bengal. Indian J Gastroenterol 32: 400-403.

10. Samanta J, Sharma V (2015) Dengue and its effects on liver. World J Clin Cases 3: 125-131.

11. Bamanikar AA (2014) Liver injury and ascites in dengue. J Assoc Physicians India 62: 290-291.

12. Syed AA, Aslam F, Hakeem H, Siddiqui F, Nasir N (2017) Frequency of worsening liver function in severe dengue hepatitis patients receiving paracetamol: A retrospective analysis of hospital data. J Pak Med Assoc 67: 400-404.

13. Niranjan R, Thakur AK, Mishra A (2016) Food allergy and eosinophilic esophagitis in India: Lack of diagnosis. Indian J Gastroenterol 35: 72-73.

14. Alcon-LePoder S, Drouet MT, Roux P, Frenkiel MP, Arborio M, et al. (2005) The secreted form of dengue virus nonstructural protein NS1 is endocytosed by hepatocytes and accumulates in late endosomes: implications for viral infectivity. J Virol 79: 11403-11411.

15. Sani Saiful Safuan MD, Han WH, Bujang MA, Ding HJ, Kiah Loon Ng, et al. (2017) Evaluation of creatine kinase and liver enzymes in identification of severe dengue. BMC Infect Dis17: 505.

16. Vinodh BN, Bammigatti C, Kumar A, Mittal V (2005) Dengue fever with acute liver failure. J Postgrad Med 51: 322-323.

17. Wang XJ, Wei HX, Jiang SC, He C, Xu XJ, et al. (2016) Evaluation of aminotransferase abnormality in dengue patients: A meta analysis. Acta Trop 156: 130-136.

18. Arora S, Nathaniel SD, Paul JC, Hansdak SG (2015) Acute liver failure in dengue haemorrhagic fever. BMJ Case Rep.
19. Aye KS, Charngkaew K, Win N, Wai KZ, Moe K, et al. (2014) Pathologic highlights of dengue hemorrhagic fever in 13 autopsy cases from Myanmar. Hum Pathol 45: 1221-1233.

20. Ayyub M, Khazindar AM, Lubbad EH, Barlas S, Alfi AY, et al. (2006) Characteristics of dengue fever in a large public hospital, Jeddah, Saudi Arabia. J Ayub Med Coll Abbottabad 18: 9-13.

21. Beltran D, Lopez-Verges S (2014) NK Cells during Dengue Disease and Their Recognition of Dengue Virus-Infected cells. Front Immunol 5: 192.

22. Bhatty S, Shaikh NA, Fatima M, Sumbhuani AK (2009) Acute acalculous cholecystitis in dengue fever. J Pak Med Assoc 59: 519-21.

23. Baig Mirza AM, Fida M, Murtaza G, Niazi R, Hanif A, et al. (2016) Association of metabolic factors with dengue viral infection on admission triage which predict its clinical course during Lahore dengue epidemic. J Pak Med Assoc 66: 1102-1106.

24. Couvelard A, Marianneau P, Bedel C, Drouet MT, Vachon F, et al. (1999) Report of a fatal case of dengue infection with hepatitis: demonstration of dengue antigens in hepatocytes and liver apoptosis. Hum Pathol 30: 1106-1110.

25. An J, Zhou DS, Zhang JL, Morida H, Wang JL, et al. (2004) Denguespecific CD8+ $\mathrm{T}$ cells have both protective and pathogenic roles in dengue virus infection. Immunol Lett 95: 167-74.

26. Avirutnan P, Zhang L, Punyadee N, Manuyakorn A, Puttikhunt C, et al. (2007) Secreted NS1 of dengue virus attaches to the surface of cells via interactions with heparan sulfate and chondroitin sulfate E. PLoS Pathog 3: e183.

27. Barth OM, Barreto DF, Paes MV, Takiya CM, Pinhao AT, Schatzmayr HG (2006) Morphological studies in a model for dengue-2 virus infection in mice. Mem Inst Oswaldo Cruz 101: 905-15.

28. Costa VV, Ye W, Chen Q, Teixeira MM, Preiser P, et al. (2017) Dengue Virus-Infected Dendritic Cells, but Not Monocytes, Activate Natural Killer Cells through a Contact-Dependent Mechanism Involving Adhesion Molecules. M Bio pp: 8.

29. Costa VV, Fagundes CT, Valadao DF, Avila TV, Cisalpino D, et al. (2014) Subversion of early innate antiviral responses during antibody-dependent enhancement of Dengue virus infection induces severe disease in immunocompetent mice. Med Microbiol Immunol 203: 231-50.

30. Chong SE, Mohamad Zaini RH, Suraiya S, Lee KT, Lim JA (2017) The dangers of accepting a single diagnosis: case report of concurrent Plasmodium knowlesi malaria and dengue infection. Malar J 16: 2.

31. Chingsuwanrote P, Suksanpaisan L, Smith DR (2004) Adaptation of the plaque assay methodology for dengue virus infected HepG2 cells. J Virol Methods 116: 119-121.

32. Colpitts TM, Barthel S, Wang P, Fikrig E (2011) Dengue virus capsid protein binds core histones and inhibits nucleosome formation in human liver cells. PloS one 6: e24365. 